\title{
A DNA barcode database for the woody plants of Japan
}

2 Suzuki Setsuko ${ }^{1}$, Kensuke Yoshimura ${ }^{1}$, Saneyoshi Ueno ${ }^{1}$, James Raymond Peter Worth ${ }^{1}$,

3 Tokuko Ujino-Ihara ${ }^{1}$, Toshio Katsuki ${ }^{2}$, Shuichi Noshiro ${ }^{3}$, Tomoyuki Fujii ${ }^{3}$, Takahisa Arai ${ }^{4}$,

4 Hiroshi Yoshimaru ${ }^{1}$

$5{ }^{1}$ Department of Forest Molecular Genetics and Biotechnology, Forestry and Forest Products Research Institute, Forest

6 Research and Management Organization, Ibaraki, Japan

$7 \quad{ }^{2}$ Tama Forest Science Garden, Forestry and Forest Products Research Institute, Forest Research and Management

8 Organization, Tokyo, Japan

$9 \quad{ }^{3}$ Department of Wood Properties and Processing, Forestry and Forest Products Research Institute, Forest Research

10 and Management Organization, Ibaraki, Japan

$11 \quad{ }^{4}$ Tohoku University Botanical Gardens, Tohoku University, Miyagi, Japan

12 Correspondence

13 Suzuki SETSUKO, Department of Forest Molecular Genetics and Biotechnology, Forestry and Forest Products

14 Research Institute, Forest Research and Management Organization, 1 Matsunosato, Tsukuba, Ibaraki 305-8687,

$15 \quad J a p a n$. E-mail: setsukos@affrc.go.jp

16 Present address

17 Toshio Katsuki, Kyushu Research Center, Kumamoto, Japan

18 Shuichi Noshiro, Center for Obsidian and Lithic Studies, Meiji University, Tokyo, Japan

19 Tomoyuki Fujii, Hiroshi Yoshimaru, Research fellow, Forest Research and Management Organization, Ibaraki,

20 Japan

21 Takahisa Arai, Kanto Regional Environment Office, Ministry of the Environment, Government of Japan, Saitama,

22 Japan 


\section{Abstract}

25

26

27

28

29

30

31

32

33

34

conifers, species discrimination, DNA barcoding, Japan, woody flora, vascular plants

DNA barcode databases are increasingly available for a range of organisms facilitating the wide application of DNA barcode-based pursuits. Here we announce the development of a comprehensive DNA barcode database of the Japanese woody flora representing 43 orders, 99 families, 303 genera and 834 species and comprising $77.3 \%$ of genera and $72.2 \%$ of species of woody plants in Japan. A total of 6,216 plant specimens were collected from 223 sites (municipalities, i.e. city, town, village) across the subtropical, temperate, boreal and alpine biomes in Japan with most species represented by multiple accessions. This database utilised three chloroplast DNA regions (rbcL, trnH-psbA and matK) and consists of 14,404 barcode sequences. Individual regions varied in their identification rates with species-level and genuslevel rates for rbcL, trnH-psbA and matK being 57.4\%/96.2\%, 78.5\%/99.1\% and 67.8\%/98\%, respectively. Identification rates were higher using region combinations with total species level rates for two region combinations ( $\mathrm{rbcL} \& \operatorname{trnH}, \operatorname{rbcL} \&$ matK, and trnH-psbA \& matK) ranging between $90.6-95.8 \%$, and for all three regions equal to $98.6 \%$. Genus level identification rates were even higher ranging between $99.7-100 \%$ for two region combinations and being $100 \%$ for the three regions. These results indicate that this DNA barcode database is an effective resource for investigations of woody plants in Japan using DNA barcodes and provides a useful template for development of libraries for other components of the Japanese flora. 


\section{1 | INTRODUCTION}

47 DNA barcodes are short DNA fragments that are able to accurately and rapidly identify to the

48 lowest taxonomic level possible (ideally to the species level) any unidentified organism

49 including whole or fragmented specimens, wood, pollen, subfossils or environmental DNA. The

50 ability to identify plant species via DNA barcoding has a great range of uses including for human

51 health (such as identifying sources of pollen (Kraaijeveld et al., 2015) or house dust (Craine et

52 al., 2017), in forensics (Ferri et al., 2015), bio-security (Ashfaq \& Hebert, 2016), nature

53 conservation (such as environmental monitoring (Fahner et al., 2016), biodiversity assessment

54 (Burgess et al., 2011) and enforcing trade laws of endangered species (Dormontt et al., 2015)),

55 agriculture (e.g. monitoring pollination and gene flow of crops (Richardson et al., 2015) and various applications for scientific research (e.g. understanding past impacts of climate change

57 (Giguet-Covex et al., 2014) or for use in plant taxonomy and species discovery (Kress et al.,

58 2015)). Creating DNA barcode libraries, that is, a collection of DNA sequences associated with specimens that have verified taxonomic identifications (Kress et al., 2015), is essential for use as a reference in order to identify unidentified samples. DNA barcoding libraries are now available for a wide range of organisms such as animals and fungi due to the availability of universal barcodes for these groups. However, unlike animals or fungi, there is no single universal DNA fragment for use in DNA barcoding of plants mostly due to the low level of mutation of organelle genomes in plants (Wolfe et al., 1987). This has made it necessary to use multi-locus

65 barcodes (Kress \& Erickson, 2007) and in some cases to develop specific barcodes for the

67 complex and time consuming. Nonetheless, in the last decade such libraries have become 
specific taxonomic groups (Liu et al., 2018; Nevill et al., 2013) or individual biomes (Costion et al., 2016; Saarela et al., 2013).

Due to the enormous effort required to completely represent the full range of genetic diversity within species in DNA barcode libraries, especially for those covering many diverse taxa, the full range of sequence diversity may not be fully captured in DNA barcode libraries. This factor, together with low sequence divergence between closely related species, which is particularly common in species rich clades, along with taxonomic uncertainty, means that reliable identification to species level can be difficult (Parmentier et al., 2013; Raupach et al., 2014). However, for many applications of DNA barcoding assignment to higher taxonomic levels, such as the genus-level, is of considerable value and, in many plant groups, accuracy of assignment at this level is more reliable than at the species level (Wilson et al., 2011).

In Japan, DNA barcode libraries have been developed for a range of taxonomic groups (Japanese DNA Barcode Database Committee, 2014). However, these have focussed exclusively on animals such as birds (Nishiumi, 2012), ticks (Takano et al., 2014), snails (Hirose et al., 2015) and snapping beetles (Oba et al., 2015) with plants, excluding ferns (Ebihara et al., 2010), so far having been overlooked. The Japanese archipelago has a highly diverse vascular plant flora with 6,000 species (of which approximately 1,000 are woody plants in 100 families (Satake et al., 1989)) of which around 2,900 are endemic (Biodiversity Center of Japan Nature Conservation Bureau Ministry of the Environment, 2010) and is one of the 35 hotspots of plant diversity in the world (Mittermeier et al., 2004).

In this paper we announce the development of a DNA barcode database for nearly the entire woody plant flora of Japan (available on the publicly available Barcode of Life Data System (BOLD: https://www.boldsystems.org (Ratnasingham \& Hebert, 2007)). This database 
92 consists of 6,216 specimens of woody plants (i.e. those plants with above ground perennial parts

93 having lignified wood formed by secondary growth) sampled from 223 sites across the entire

94 Japanese Archipelago representing subtropical, temperate, boreal and alpine biomes with

95 multiple accessions collected across the range of each species where possible (Figure 1). We

96 utilized three chloroplast regions ( $\mathrm{rbcL}$, matK and trnH-psbA) which have become widely used

97 in plant DNA barcoding studies and have achieved high rates of species resolution (Burgess et

98 al., 2011; Kress et al., 2009).

99

100

2 | MATERIALS AND METHODS

101

\section{1 | Laboratory Work}

Leaf samples for DNA extraction were collected from 223 sites across the whole of the Japanese

Archipelago (Figure 1). These sites encompass all major vegetation types and biomes of Japan.

104 For each sample, the latitude and longitude were recorded and identification was done to the

105 lowest taxonomic level possible (i.e. subspecies or variety). For $92.4 \%$ of samples, voucher

106 herbarium specimens were prepared and stored in the herbaria in Japan. Most of them are housed

107 in the xylarium (TWTw) and herbarium (TF) of the Forestry and Forest Products Research

108 Institute (FFPRI), and most images of these voucher herbarium specimens are available at the

109 database of Japanese Woods, FFPRI (https://db.ffpri.go.jp/WoodDB/index-E.html) and BOLD

110 SYSTEMS. The rest vouchers of the samples are housed in the herbaria of Tohoku University

111 Botanical Garden herbarium (TUS) and Herbarium of the Kyushu University Museum (FU) in

112 Japan (Specimen details including museum ID together with GenBank ID and BOLD process ID

113 is available from Supplementary table 1 and BOLD SYSTEMS). 

instructions. For each sample we aimed to sequence three chloroplast barcode regions (rbcL, matK and trnH-psbA). The rbcL gene is easily amplified across land plants and, although it does

117 not have sufficient variability to be used alone as a species discriminator, is considered a reliable 118 'benchmark' locus for placing taxa into family and genera (Kress \& Erickson, 2007). matK is 119 one of the most variable coding regions found in chloroplast DNA (Shaw et al., 2005), while the 120 non-coding trnH-psbA region has highly conserved priming sites across land plants and high 121 sequence divergence (Kress \& Erickson, 2007). The first two of these fragments, rbcL and matK, 122 have been adopted by the Consortium for the Barcode of Life (CBOL) (CBOL Plant Working 123 Group, 2009) as the core 2-locus barcode for plants while trnH-psbA has been widely used as a 124 single locus or in combination with other loci (Pang et al., 2012; Yao et al., 2009). To amplify 125 the barcode regions ( $\mathrm{rbcL}$, matK and trnH-psbA) we first tested primers recommended by the 126 CBOL Plant Working Group (CBOL Plant Working Group, 2009; Hamilton, 1999). However, 127 due to poor amplification and sequence quality, new primers to amplify both rbcL (reverse only) 128 trnH-psbA (both forward and reverse) regions were designed by consulting the whole chloroplast 129 genomes of tobacco, rice and Japanese black pine (Table 1). For the matK region, we also designed a new reverse primer by consulting the matK sequence of Hydrangea macrophylla, and 131 trialled a two-step PCR approach following Forrest et al. (2011) with separate primer pairs for 132 each step (Table 1). However, due to poor amplification success of matK in some orders or, in 133 some cases, families, we developed new targeted primers. For those orders and/or families, 134 where amplification of matK was poor we downloaded available chloroplast sequences from 135 Genbank and developed new targeted primers (Table 1). 
The PCR reaction mixture contained $0.05 \mu \mathrm{Ex}$ Taq polymerase ( $5 \mathrm{U} / \mu \mathrm{l}$, TAKARA), $1 \mu 1$ 10X Ex Taq Buffer (20 mM, $\mathrm{Mg}^{2+}$ plus), $0.8 \mu \mathrm{dNTP}$ Mixture (2.5 mM each), $0.5 \mu$ forward and reverse primer (each $2 \mu \mathrm{M}$ ), and $2 \mu$ template DNA (approximately $10 \mathrm{ng}$ ) in $10 \mu \mathrm{l}$ total volume. PCRs were carried out using the following thermocycle: $94{ }^{\circ} \mathrm{C}$ for 3 min, then 35 cycles of $94{ }^{\circ} \mathrm{C}$ for 30 s, each annealing temperature for $60 \mathrm{~s}, 72^{\circ} \mathrm{C}$ for 90 s, followed by final extension

141 at $72{ }^{\circ} \mathrm{C}$ for $10 \mathrm{~min}$. Amplicon products were sent to TAKARA Bio (Mie, Japan) and Hokkaido

142 System Science (Sapporo, Japan) for DNA sequencing or, alternatively, sequenced using an ABI3100 Genetic Analyzer (Applied Biosystems) at the FFPRI, Tsukuba, Ibaraki Prefecture. We used not only KB Basecaller (Applied Biosystems) but also PeakTrace software (Nucleics) for accurate base calling in some sequences. Sequences for rbcL and trnH were checked by eye using Sequencher (Hitachi) and aligned in Bioedit (Hall 1994). Those for matK were checked and aligned by CodonCode Aligner (CodonCode Corporation, www.codoncode.com).

\section{2 | Data analysis}

Firstly, in order to grasp how well the database represents the total native woody plants of Japan we calculated the percentage of genera and species native to Japan included in the database per family using the most comprehensive reference available (The wild woody plants of Japan

153 volumes I and II; Satake et al. 1989). In addition, we calculated the proportion of the flora 154 included in the database for each of six regions of Japan (Hokkaido, Honshu, Shikoku, Kyushu,

155 Nansei and Ogasawara Islands) with the distribution of each species based on Satake et al.

156 (1989). Where new additions or changes to the woody plants have been made that are not listed

157 in Satake et al. (1989) these were not taken into account in the calculations. For woody plants

158 not listed in Satake et al. (1989), we included as many as possible from the 223 sites and 
159 included them in the database. For taxonomic classifications we followed the most recent

160 available (Green List (Ito et al., 2016) or, for those not listed on Green List, we followed YList

161 (Yonekura \& Kajita, 2003)). The taxonomic classification used for BOLD is shown in

162 Supplementary table 1. Any disagreement in classification at the order or family level between

163 Green List and/or YList is also indicated.

The success rate of sequencing was calculated as the proportion of the number of high-

165 quality sequences obtained to the total number of samples. The species identification ability of

166 each barcode was evaluated using the BLAST method (Altschul et al., 1990). BLAST databases

167 were constructed not only for each region (rbcL, matK and trnH-psbA), but also combined

168 regions (rbcL \& matK, matK \& trnH-psbA, trnH-psbA \& rbcL, and all three regions). Sequences

169 were concatenated and used in the BLAST databases if sequences were available. Nucleotide

170 BLAST (blastn) search was carried out for each sequence in each database against its own

171 database (i.e. a self-blast) with default parameters. If the top hit sequence species name was the

172 same as that of the query sequence and was the highest BLAST hit score, we considered the

173 query sequence was successfully identified at the species level. However, if multiple top BLAST

174 hits had the same score, the query was considered to not be identifiable to the species level. In

175 the case that the multiple top BLAST hits contained only sequences of the same genus or family

176 as that of query sequence, it was considered to be identified at genus or family level,

177 respectively. 
180 To confirm the consistency of the data we constructed, a phylogenetic tree based on the three

181 region barcode sequences of angiosperms included in the Japanese woody plant database and

182 compared the result to published angiosperm phylogenies (The Angiosperm Phylogeny Group,

$1832003,2009,2016)$. To do so, for each angiosperm family one representative individual sample

184 with the longest concatenated sequence of the three regions was selected. Sequence alignment

185 was undertaken in Geneious version 2019.0.4 using Muscle alignment (Edgar, 2004) with

186 default parameters. Phylogenetic analysis was undertaken using a Bayesian MCMC approach

187 implemented in MrBayes v 3.2 (Ronquist et al., 2012) and run with 400,000 MCMC generations,

1884 chains and sample frequency of 100 and implementing the most parameter-rich substitution

189 model, GTR+I+G, which has been shown to perform equally well as specifically selected

190 models (Abadi et al., 2019). A sequence of the basal angiosperm family Schisandraceae

191 (Austrobaileyales) was selected as an outgroup (The Angiosperm Phylogeny Group, 2003, 2009,

192 2016). A consensus tree was produced using the sumt burnin=0.25 command and was then

193 edited in FigTree v1.4.4 (Rambaut, 2020).

In total, 14,404 barcode sequences from 6,216 woody plant specimens were included in the

197 database (Table 2). The average number of accessions per species was 7.5 and ranged from a

198 single accession to a maximum of 73. Our database included 43 orders, 99 families, 303 genera,

199834 species with 953 taxa which represented $77.3 \%$ of woody plant genera and $72.2 \%$ of woody

200 plant species recognised by Satake et al. (1989). The missing species included those that are rare

201 or have restricted ranges on islands, high mountain tops or serpentine regions or were otherwise 
202

203

204

205

206

207

208

209

210

211

212

213

214

215

216

217

218

219

220

221

223

224

not encountered at the 223 collection sites. The sampling rate for each geographic region ranged between $84.3-88.9 \%$ except for the Nansei Islands (63.3\%, Table 3).

The total sequence success for rbcL, trnH-psbA and matK were 96.2, 76.4 and 59.1\%, respectively (Figure 2a). We obtained rbcL for all orders sampled while trnH-psbA did not amplify in one order (Araucariales, Figure 3a). The amplification of matK had been lower (45.0\%) with no amplification in 14 orders consisting of 17 families including all gymnosperms when we used a two-step PCR approach (data not shown). However, the use of newly developed targeted primers (Table 1) resulted in the number of orders where matK was not amplifiable decreasing from 14 to 4 consisting of 10 families, and showed high sequence success rate in gymnosperms (Figure 3a, Supplementary table 2, 3).

Total identification rates for rbcL were as follows: $57.4 \%$ of samples returned a species level match, 96.2\% a genus level match and 100\% a family level match (Figure 2b). For trnHpsbA, there was greater identification rate with $78.5 \%$ returning a species level match, $99.1 \%$ at genus level and $100 \%$ at the family level. For matK the identification rates were middle range with $67.8 \%$ returning a species level match, $98.1 \%$ at the genus level and $100 \%$ at the family level. Total identification rate at species level for two region combinations (rbcL \& trnH, rbcL \& matK, and trnH-psbA \& matK) ranged between 90.6-95.8\%, and for all three regions was 98.6\%. Total identification rate at genus level for two region combinations (rbcL \& trnH-psbA, rbcL \& matK, and trnH-psbA \& matK) ranged between $99.7-100 \%$, and for three regions was $100 \%$.

There were some similar taxonomic patterns across the three regions for identification rate (Figure 3b). Some species rich orders had a tendency for low species level identification rate based on the individual regions such as Pinales, Pandanales, Rosales and Fagales. The lowest 
225 order-based identification rate for each region was $33.3 \%$ for rbcL, $50.0 \%$ for trnH (both

226 Pandanales) and 40.5\% for matK (Pinales) (Supplementary table 3). For 18 families that were

227 well sampled and sequenced (i.e. over $70 \%$ of species represented and over $50 \%$ of sequence

228 success for all three regions) and have relatively high species diversity (over 10), we found that

229 identification rate at the species level was high using all three regions combined (Figure 4). Only

230 two families had identification rate below 95\% (Pinaceae $=91.8 \%$ and Rosaceae $=93.5 \%$ ).

231 Interestingly, despite low species-level identification rates based on each individual region

$232(25.7-66.0 \%)$, the combined data resulted in a 99.2\% successful identification rate for Fagaceae

233 (Figure 4). High identification rates at each individual region of 85.4-97.8\% were observed in

234 Rutaceae. The identification rates at the family, genus and species levels for all families is

235 provided in Supplementary table 3.

The phylogenetic tree of Japanese native angiosperm woody plants was well resolved

237 with most nodes having branch-support values over 95\%. In addition, the phylogenetic tree has

238 similar overall relationships to published angiosperm phylogenies (Figure 5) (The Angiosperm

239 Phylogeny Group, 2003, 2009, 2016).

2414 |DISCUSSION

242 This barcode database of Japanese woody plants provides a valuable resource for a range of

243 applications in scientific, government and commercial pursuits. The high representation of

244 woody plant species and multiple accessions per species make it one of the most comprehensive

245 barcode libraries of any taxonomic group in the country to date. This database is significant

246 advancement in terms of the barcode resources available for the Japanese flora with the only 
247 previous barcode database being for ferns (Ebihara et al., 2010). For well sampled families the

248 species identification rate achieved using all three barcodes was high (over 90\%). The database

249 can be accessed and samples analysed directly at the Barcode of Life Data System website

250 (BOLD: Ratnasingham \& Hebert (2007)), GenBank and ForestGEN

251 (https://forestgen.ffpri.go.jp/jp/index.html) or alternatively, data exported and analysed in other

252 programs (e.g. Sonet et al., 2013; Steinke et al., 2005; Vences et al., 2021). In the case that an

253 unknown samples sequence is not included in the database identification to the nearest species

254 and/or genus is likely to be accurate. Identification accuracy of unknown samples may be

255 improved by utilising specific programs that take into account identification uncertainty due to

256 incomplete sampling of sequence diversity (Sonet et al., 2013).

Based on this database, the utility of each individual region differed substantially. rbcL

had the highest sequence success rate but the lowest species-level identification rate. matK had

259 the lowest sequence success rate and moderate species-level identification rate. In contrast, trnH-

260 psbA had moderate sequencing success but the highest species-level identification rate. The

261 CBOL Plant Working Group recommend the rbcL and matK combination as a standard barcode

262 for land plants with trnH-psbA not included due to alignment issues caused by high variability

263 including at mononucleotide repeats. However, if the application of barcodes is focussed at the

264 family or genus level trnH-psbA is useful for species level identification given its high

265 variability. On the hand, the rbcL and matK pair is more appropriate than trnH-psbA for

266 revealing phylogenetic relationships across a diverse range of taxonomic groups. Lastly, we

267 show that for orders where PCR amplification using universal primers was poor the development

268 of targeted primers can significantly improve results. This was especially evident in

269 gymnosperms and Sapindales where improvements of up to $100 \%$ were observed for matK 
270 (Supplementary table 2). This finding suggests that for reliable use of matK in DNA barcode

271 libraries the development of targeted primers may be necessary.

The lowest species level identification rates based on individual regions were observed in

273 Pinales, Pandanales, Rosales and Fagales. Rosales and Fagales have high species diversity but

274 are also characterised by families where recurrent past or ongoing gene flow via hybridisation

275 and/or hybrid species is widespread in Japan (Iwatsuki et al., 1999, 2001, 2006). In contrast,

276 Pinales have lower number of species but undergo extensive chloroplast sharing resulting in a

277 lower identification rate in some genera (Aizawa \& Iwaizumi, 2020; Watano et al., 2004).

278 Similar identification rates have been observed in European Pinus (Celiński et al., 2017).

279 Hybridisation between congeneric species can lead to chloroplast haplotype sharing (McKinnon

280 et al., 1999; Petit et al., 2002) which in some cases makes species level identification difficult or

281 even impossible, especially using a single chloroplast-based barcode. However, despite this even

282 for orders with low species level identification rates based on individual regions such as Pinales,

283 Rosales and Fagales, identification rates were over $90 \%$ using all three regions. Another reason

284 for low species level identification rates observed in this study is exemplified by the genus

285 Pandanus whose two Japanese species occur on separate islands but due to very recent

286 speciation have not diverged at the chloroplast.

The availability of the Japanese woody plant barcode database is likely to open new

288 avenues for scientific research and environmental monitoring in Japan. DNA Barcodes combined

289 with NGS technology have already formed the basis of new, powerful and less invasive

290 approaches to environmental monitoring in other organisms. For example, DNA barcodes for

291 fish species used in metabarcoding of environmental DNA from seawater samples has the

292 potential to revolutionize management of fish resources in Japan (Miya et al., 2015) by 
293 improving the accuracy of assessments of fish species diversity (Yamamoto et al., 2017) and

294 providing a new tool to assess fish species biomass (Yamamoto et al., 2016). Some research

295 fields where DNA barcodes for Japanese woody plants may have significant impact, either as the

296 sole investigative tool or together with existing methods, includes assessing present diversity of

297 plants in biodiversity surveys (Taberlet et al., 2012; Yoccoz et al., 2012), diet analysis of

298 endangered or invasive animals (Ando et al., 2013; Nakahama et al., 2021), or monitoring of

299 pollen sources (Nakazawa et al., 2013). The database could also have applications aimed at

300

301

302

303

304

305

306

307

308

309

310

311 surveying past plant diversity from the decade to potentially thousands of years scale. For

example, DNA metabarcoding could be a useful tool in deciphering the plant species

composition of natural vegetation before conversion to plantations in the mid-late $20^{\text {th }}$ century.

Reconversion to native forest and grasslands of some areas of under-exploited plantations in

Japan has been an important issue in the last decade (Yamaura et al., 2012) but given that

plantation forests can cover large areas, with up to $66 \%$ of totals forest area in parts of

southwestern Japan being planted forests (Forestry Agency, 2017), understanding past natural

vegetation can be difficult. Chloroplast DNA barcodes are highly suited to investigations using degraded samples, including ancient DNA, because of the high copy number of chloroplast in plant cells (Wagner, 1992). However, given that shorter DNA fragments survive for longer

(Deiner et al., 2017), optimization of shorter targeted fragments of the three barcodes would most likely be required.

The barcode database for Japanese woody plants announced in this paper provides a valuable resource for both research and non-research-based pursuits investigating the countries flora. Due to the high species diversity and high number of geographically restricted species constructing a barcode database for the entire Japanese flora was not considered feasible in one 
study. However, we hope that this study provides a useful template from which further countryor region-based databases can be developed including for herbaceous plants and rare species that were not targeted in this study. For this database the use of nuclear loci such as the internal transcribed spacer (ITS) was not considered because of poor amplification success across land plants (Hollingsworth, 2011) and paralogous copies (Poczai \& Hyvönen, 2010). However, future studies, especially those focussed on specific taxonomic groups, could have success using the shorter ITS2 region (China Plant B. O. L. Group et al., 2011), or potentially other low copy nuclear loci (Kurian et al., 2020).

\section{ACKNOWLEDGEMENTS}

We would like to thank Y. Tsumura, T. Kawahara, M. Ohtani (FFPRI), M. Ito (The University of Tokyo) and H. Tachida (Kyushu University) for their valuable advice. We also thank, K. Ishida (Hirosaki University), H. Sakio, M. Nakata (Niigata University), N. Matsushita (The University of Tokyo), Y. Mukai, Shogo Kato (Gifu University), I. Tamaki, N. Yanagisawa (Gifu Academy of Forest Science and Culture), Y. Watanabe (Nagoya University), H. Kisanuki (Mie University), H. Ando, M. Yamazaki, S. Sakaguchi (Kyoto University), T. Yahara (Kyushu University), M. Takagi (University of Miyazaki), H. Taoda, K. Sugai, Shuri Kato, S. Kikuchi and T. Nagamitsu (FFPRI) for collecting samples and Y. Kawamata, A. Hisamatsu and C. Furusawa (FFPRI) for their assistance with laboratory work. This work was supported by a Grant-in-Aid for Scientific Research $(20248017,25292098)$ from the Japan Society for the Promotion of Science, and the support program of FFPRI for researchers having family responsibilities. 


\section{AUTHOR CONTRIBUTIONS}

340 Hiroshi Yoshimaru, Kensuke Yoshimura and Suzuki Setsuko conceived and designed the

341 research. Toshio Katsuki, Shuichi Noshiro, Tomoyuki Fujii and Takahisa Arai conducted the

342 field work. Hiroshi Yoshimaru, Kensuke Yoshimura, Takahisa Arai and Suzuki Setsuko

343 conducted the laboratory work. Hiroshi Yoshimaru, Kensuke Yoshimura, Saneyoshi Ueno,

344 James Raymond Peter Worth, Tokuko Ujino-Ihara and Suzuki Setsuko analyzed the data. James

345 Raymond Peter Worth, Saneyoshi Ueno and Suzuki Setsuko wrote the manuscript. All authors

346 contributed to the final submitted manuscript.

\section{DATA AVAILABILITY STATEMENT}

349 Specimen data and DNA barcodes: BOLD and Genbank accessions are listed with specimen 350 metadata in supporting information.

\section{ORCID}

353 Suzuki Setsuko: https://orcid.org/0000-0002-0612-1853

354 Saneyoshi Ueno: https://orcid.org/0000-0001-5571-0622

355 James Raymond Peter Worth: https://orcid.org/0000-0003-2020-2470

356 Tokuko Ujino-Ihara: https://orcid.org/0000-0002-9243-1638

357 Tomoyuki Fujii: https://orcid.org/0000-0002-6552-5639 
bioRxiv preprint doi: https://doi.org/10.1101/2021.11.11.468310; this version posted November 12, 2021. The copyright holder for this preprint (which was not certified by peer review) is the author/funder, who has granted bioRxiv a license to display the preprint in perpetuity. It is made available under aCC-BY 4.0 International license.

358 Hiroshi Yoshimaru: https://orcid.org/0000-0002-0688-5589 


\section{REFERENCES}

Abadi S, Azouri D, Pupko T, Mayrose I (2019) Model selection may not be a mandatory step for phylogeny reconstruction. Nature communications, 10(1), 934.

Aizawa M, Iwaizumi MG (2020) Natural hybridization and introgression of Abies firma and Abies homolepis along the altitudinal gradient and genetic insights into the origin of Abies umbellata. Plant Species Biology, 35(2), 147-157.

Altschul SF, Gish W, Miller W, Myers EW, Lipman DJ (1990) Basic local alignment search tool. J Mol Biol, 215(3), 403-410.

Ando H, Setsuko S, Horikoshi K, et al. (2013) Diet analysis by next-generation sequencing indicates the frequent consumption of introduced plants by the critically endangered red-headed wood pigeon (Columba janthina nitens) in oceanic island habitats. Ecol Evol, 3(12), 4057-4069.

Ashfaq M, Hebert PDN (2016) DNA barcodes for bio-surveillance: regulated and economically important arthropod plant pests. Genome, 59(11), 933-945.

Biodiversity Center of Japan Nature Conservation Bureau Ministry of the Environment (2010) Biodiversity of Japan : a harmonious coexistence between nature and humankind. Tokyo: Heibonsha.

Burgess KS, Fazekas AJ, Kesanakurti PR, et al. (2011) Discriminating plant species in a local temperate flora using the rbcL+ matK DNA barcode. Methods in Ecology and Evolution, 2(4), 333-340.

CBOL Plant Working Group (2009) A DNA barcode for land plants. Proc Natl Acad Sci U S A, 106(31), 1279412797.

Celiński K, Kijak H, Wojnicka-Półtorak A, et al. (2017) Effectiveness of the DNA barcoding approach for closely related conifers discrimination: A case study of the Pinus mugo complex. Comptes Rendus Biologies, 340(6), 339-348.

China Plant B. O. L. Group, Li D-Z, Gao L-M, et al. (2011) Comparative analysis of a large dataset indicates that internal transcribed spacer (ITS) should be incorporated into the core barcode for seed plants. Proceedings of the National Academy of Sciences, 108(49), 19641-19646.

Costion CM, Lowe AJ, Rossetto M, et al. (2016) Building a plant DNA barcode reference library for a diverse tropical Flora: an example from Queensland, Australia. Diversity, 8(1), 5-5.

Craine JM, Barberán A, Lynch RC, et al. (2017) Molecular analysis of environmental plant DNA in house dust across the United States. Aerobiologia, 33(1), 71-86.

de Vere N, Rich TCG, Ford CR, et al. (2012) DNA barcoding the native flowering plants and conifers of Wales. PLoS One, 7(6).

Deiner K, Bik HM, Mächler E, et al. (2017) Environmental DNA metabarcoding: Transforming how we survey animal and plant communities. Molecular ecology, 26(21), 5872-5895.

Dormontt EE, Boner M, Braun B, et al. (2015) Forensic timber identification: It's time to integrate disciplines to combat illegal logging. Biological Conservation, 191, 790-798.

Dunning LT, Savolainen V. (2010) Broad-scale amplification of matK for DNA barcoding plants, a technical note. Botanical Journal of the Linnean Society, 164(1), 1-9. 
Ebihara A, Nitta JH, Ito M (2010) Molecular species identification with rich floristic sampling: DNA barcoding the pteridophyte flora of Japan. PLoS One, 5(12), e15136.

Edgar RC (2004) MUSCLE: multiple sequence alignment with high accuracy and high throughput. Nucleic Acids Research, 32(5), 1792-1797.

Fahner NA, Shokralla S, Baird DJ, Hajibabaei M (2016) Large-scale monitoring of plants through environmental DNA metabarcoding of soil: recovery, resolution, and annotation of four DNA markers. PLoS One, 11(6).

Ferri G, Corradini B, Ferrari F, et al. (2015) Forensic botany II, DNA barcode for land plants: Which markers after the international agreement? Forensic Science International: Genetics, 15, 131-136.

Forestry Agency (2017) Status of forest resources. Proportion of forest and planted forest for each prefectures in Japan. Retrieved from https://www.rinya.maff.go.jp/j/keikaku/genkyou/h29/1.html

Forrest A, Hollingsworth P, Little D, et al. (2011) Plant DNA Barcoding using matK, some work in new primer sets Retrieved from https://www.slideshare.net/CBOLAdelaide2011/thursday-napier-lg29-1100-hollingsworthmat-k-primers.

Giguet-Covex C, Pansu J, Arnaud F, et al. (2014) Long livestock farming history and human landscape shaping revealed by lake sediment DNA. Nature communications, 5(1), 1-7.

Hamilton MB (1999) Four primer pairs for the amplification of chloroplast intergenic regions with intraspecific variation. Molecular Ecology, 8(3), 521-523.

Hirose M, Hirose E, Kiyomoto M (2015) Identification of five species of Dendrodoris (Mollusca: Nudibranchia) from Japan, using DNA barcode and larval characters. Marine Biodiversity, 45(4), 769-780.

Hollingsworth PM (2011) Refining the DNA barcode for land plants. Proceedings of the National Academy of Sciences, 108(49), 19451-19452.

Ito M, Nagamasu H, Fujii S, et al. (2016) GreenList ver. 1.01. Retrieved from http://www.rdplants.org/gl/

Iwatsuki K, Boufford D, Ohba H (1999) Flora of Japan Vol. IIc. Angiospermae Dicotyledoneae Archlamydeae (c). In: Kodansha, Tokyo.

Iwatsuki K, Boufford D, Ohba H (2001) Flora of Japan Vol. IIb. Angiospermae Dicotyledoneae Archlamydeae (b). In: Kodansha, Tokyo.

Iwatsuki K, Boufford D, Ohba H (2006) Flora of Japan Vol. IIa. Angiospermae Dicotyledoneae Archlamydeae (a). In: Kodansha, Tokyo.

Japanese DNA Barcode Database Committee (2014) Japanese DNA Barcode Database (JBOL-DB). Retrieved from http://db.jboli.org/?locale=en

Kim S, Kim C-B, Min G-S, et al. (2012) Korea barcode of life database system (KBOL). Animal cells and systems, 16(1), 11-19.

Kraaijeveld K, De Weger LA, Ventayol García M, et al. (2015) Efficient and sensitive identification and quantification of airborne pollen using next - generation DNA sequencing. Molecular Ecology Resources, 15(1), 8-16.

Kress WJ, Erickson DL (2007) A two-locus global DNA barcode for land plants: the coding rbcL gene complements the non-coding trnH-psbA spacer region. PLoS One, 2(6). 
Kress WJ, Erickson DL, Jones FA, et al. (2009) Plant DNA barcodes and a community phylogeny of a tropical forest dynamics plot in Panama. Proceedings of the National Academy of Sciences, 106(44), 18621-18626.

Kress WJ, García-Robledo C, Uriarte M, Erickson DL (2015) DNA barcodes for ecology, evolution, and conservation. Trends in ecology \& evolution, 30(1), 25-35.

Kurian A, Dev SA, Sreekumar VB, Muralidharan EM (2020) The low copy nuclear region, RPB2 as a novel DNA barcode region for species identification in the rattan genus Calamus (Arecaceae). Physiology and molecular biology of plants : an international journal of functional plant biology, 26(9), 1875-1887.

Liu J, Milne RI, Möller M, et al. (2018) Integrating a comprehensive DNA barcode reference library with a global map of yews (Taxus L.) for forensic identification. Molecular Ecology Resources, 18(5), 1115-1131.

McKinnon GE, Steane DA, Potts BM, Vaillancourt RE (1999) Incongruence between chloroplast and species phylogenies in Eucalyptus subgenus Monocalyptus (Myrtaceae). American Journal of Botany, 86(7), 10381046.

Mittermeier RA, Gil PR, Hoffman M, et al. (2004) Hotspots Revisited: Earth's Biologically Richest and Most Endangered Terrestrial Ecoregions Cemex.

Miya M, Sato Y, Fukunaga T, et al. (2015) MiFish, a set of universal PCR primers for metabarcoding environmental DNA from fishes: detection of more than 230 subtropical marine species. Royal Society Open Science, 2(7), 150088.

Nakahama N, Furuta T, Ando H, et al. (2021) DNA meta-barcoding revealed that sika deer foraging strategies vary with season in a forest with degraded understory vegetation. Forest Ecology and Management, 484, 118637.

Nakazawa F, Uetake J, Suyama Y, et al. (2013) DNA analysis for section identification of individual Pinus pollen grains from Belukha glacier, Altai Mountains, Russia. Environmental Research Letters, 8, 014032.

Nevill PG, Wallace MJ, Miller JT, Krauss SL (2013) DNA barcoding for conservation, seed banking and ecological restoration of Acacia in the Midwest of Western Australia. Molecular Ecology Resources, 13(6), 10331042.

Nishiumi I (2012) DNA barcoding and species classification of Japanese birds. Japanese Journal of Ornithology, 61(2), 223-237.

Oba Y, Ôhira H, Murase Y, Moriyama A, Kumazawa Y (2015) DNA barcoding of Japanese click beetles (Coleoptera, Elateridae). PLoS One, 10(1), e0116612.

Pang X, Liu C, Shi L, et al. (2012) Utility of the trnH-psbA intergenic spacer region and its combinations as plant DNA barcodes: a meta-analysis. PLoS One, 7(11).

Parmentier I, Duminil Jm, Kuzmina M, et al. (2013) How effective are DNA barcodes in the identification of African rainforest trees? PLoS One, 8(4).

Petit RJ, Csaikl UM, Bordács S, et al. (2002) Chloroplast DNA variation in European white oaks: phylogeography and patterns of diversity based on data from over 2600 populations. Forest Ecology and Management, 156(1-3), 5-26. 
Poczai P, Hyvönen J (2010) Nuclear ribosomal spacer regions in plant phylogenetics: problems and prospects. Molecular biology reports, 37(4), 1897-1912.

Ragupathy S, Newmaster SG, Murugesan M, Balasubramaniam V (2009) DNA barcoding discriminates a new cryptic grass species revealed in an ethnobotany study by the hill tribes of the Western Ghats in southern India. Molecular Ecology Resources, 9, 164-171.

Rambaut A (2020) FigTree v1.4.4. Institute of Evolutionary Biology, University of Edinburgh, Edinburgh. Retrieved from http://tree.bio.ed.ac.uk/software/figtree/

Ratnasingham S, Hebert PDN (2007) BOLD: The Barcode of Life Data System (http://www.barcodinglife.org). Molecular Ecology Notes, 7(3), 355-364.

Raupach MJ, Hendrich L, Küchler SM, et al. (2014) Building-up of a DNA barcode library for true bugs (Insecta: Hemiptera: Heteroptera) of Germany reveals taxonomic uncertainties and surprises. PLoS One, 9(9).

Richardson RT, Lin CH, Sponsler DB, et al. (2015) Application of ITS2 metabarcoding to determine the provenance of pollen collected by honey bees in an agroecosystem. Applications in plant sciences, 3(1), 1400066-1400066.

Ronquist F, Teslenko M, van der Mark P, et al. (2012) MrBayes 3.2: efficient Bayesian phylogenetic inference and model choice across a large model space. Syst Biol, 61(3), 539-542.

Saarela JM, Sokoloff PC, Gillespie LJ, Consaul LL, Bull RD (2013) DNA barcoding the Canadian Arctic flora: core plastid barcodes (rbcL+ matK) for 490 vascular plant species. PLoS One, 8(10).

Satake Y, Hara H, Watari S, Tominari T (1989) Wild flowers of Japan: Woody plants I, II. Tokyo: Heibonsha Ltd., Publishers. In: Japanese.

Shaw J, Lickey EB, Beck JT, et al. (2005) The tortoise and the hare II: relative utility of 21 noncoding chloroplast DNA sequences for phylogenetic analysis. American Journal of Botany, 92(1), 142-166.

Sonet G, Jordaens K, Nagy ZT, et al. (2013) Adhoc: an R package to calculate ad hoc distance thresholds for DNA barcoding identification. ZooKeys(365), 329-329.

Steinke D, Vences M, Salzburger W, Meyer A (2005) TaxI: a software tool for DNA barcoding using distance methods. Philosophical Transactions of the Royal Society B: Biological Sciences, 360(1462), 1975-1980.

Taberlet P, Coissac E, Pompanon F, Brochmann C, Willerslev E (2012) Towards next-generation biodiversity assessment using DNA metabarcoding. Mol Ecol, 21(8), 2045-2050.

Takano A, Fujita H, Kadosaka T, et al. (2014) Construction of a DNA database for ticks collected in Japan: application of molecular identification based on the mitochondrial 16S rDNA gene. Medical Entomology and Zoology, 65(1), 13-21.

The Angiosperm Phylogeny Group (2003) An update of the Angiosperm Phylogeny Group classification for the orders and families of flowering plants: APG II. Botanical Journal of the Linnean Society, 141(4), 399-436.

The Angiosperm Phylogeny Group (2009) An update of the Angiosperm Phylogeny Group classification for the orders and families of flowering plants: APG III. Botanical Journal of the Linnean Society, 161(2), 105121.

The Angiosperm Phylogeny Group (2016) An update of the Angiosperm Phylogeny Group classification for the orders and families of flowering plants: APG IV. Botanical Journal of the Linnean Society, 181(1), 1-20. 
507

508

509

510

511

512

513

514

515

516

517

518
Vences M, Miralles A, Brouillet S, et al. (2021) iTaxoTools 0.1: Kickstarting a specimen-based software toolkit for taxonomists. BioRxiv.

Wagner DB (1992) Nuclear, chloroplast, and mitochondrial DNA polymorphisms as biochemical markers in population genetic analyses of forest trees. New Forests, 6(1-4), 373-390.

Watano Y, Kanai A, Tani N (2004) Genetic structure of hybrid zones between Pinus pumila and P. parviflora var. pentaphylla (Pinaceae) revealed by molecular hybrid index analysis. American Journal of Botany, 91(1), 65-72.

Wilson JJ, Rougerie R, Schonfeld J, et al. (2011) When species matches are unavailable are DNA barcodes correctly assigned to higher taxa? An assessment using sphingid moths. BMC Ecology, 11(1), 18-18.

Wolfe KH, Li W-H, Sharp PM (1987) Rates of nucleotide substitution vary greatly among plant mitochondrial, chloroplast, and nuclear DNAs. Proceedings of the National Academy of Sciences, 84(24), 9054-9058.

Yamamoto S, Masuda R, Sato Y, et al. (2017) Environmental DNA metabarcoding reveals local fish communities in a species-rich coastal sea. Scientific Reports, 7(1), 40368.

Yamamoto S, Minami K, Fukaya K, et al. (2016) Environmental DNA as a 'snapshot' of fish distribution: A case study of Japanese jack mackerel in Maizuru Bay, Sea of Japan. PLoS One, 11(3), e0149786.

Yamaura Y, Oka H, Taki H, Ozaki K, Tanaka H (2012) Sustainable management of planted landscapes: lessons from Japan. Biodiversity and Conservation, 21(12), 3107-3129.

Yao H, Song J-Y, Ma X-Y, et al. (2009) Identification of Dendrobium species by a candidate DNA barcode sequence: the chloroplast psbA-trnH intergenic region. Planta medica, 75(06), 667-669.

Yoccoz NG, Bråthen KA, Gielly L, et al. (2012) DNA from soil mirrors plant taxonomic and growth form diversity. Mol Ecol, 21(15), 3647-3655.

Yonekura K, Kajita T (2003) BG Plants: Japanese name-scientific name index (YList). Retrieved from http://ylist.info 
532 Table 1 Details of the primer DNA sequences for each of the three chloroplast barcode regions.

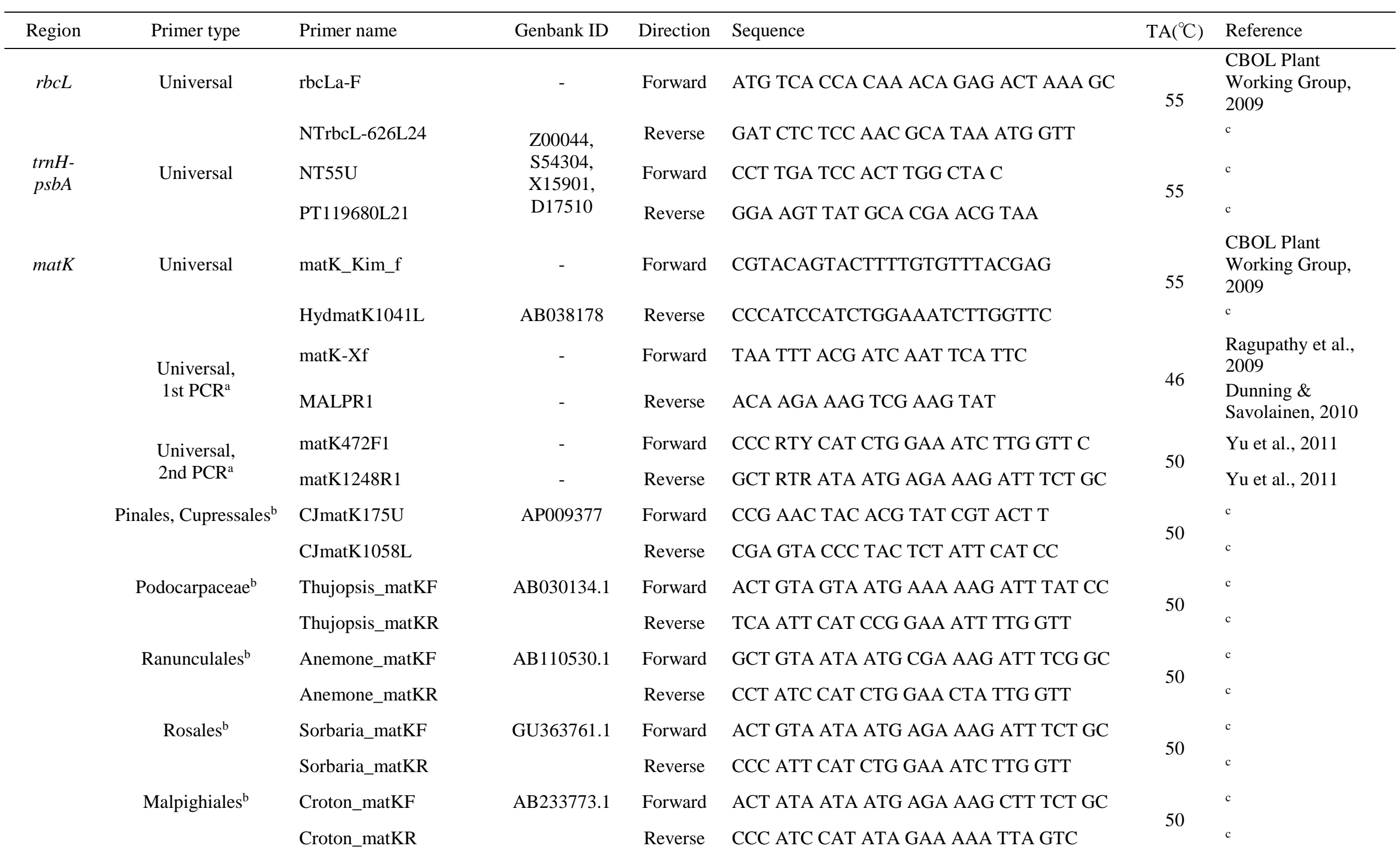




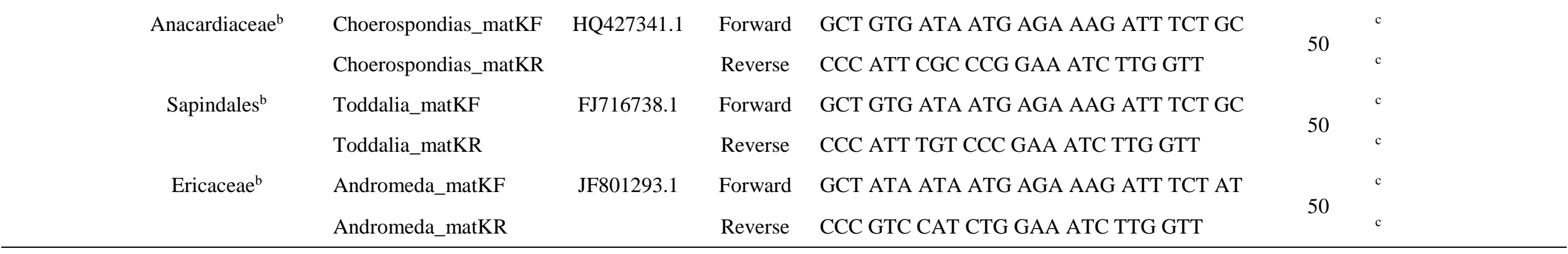

533

534 a Two step PCR was carried out in matK according to Forrest et al. (2011)

$535 \mathrm{~b}$ Tageted primers in matK

$536{ }^{c}$ Primers designed for use in this study. 
537 Table 2 A summary of the representation of genera and species of each plant order native to 538 Japan included in the Japanese woody plants DNA barcoding database.

\begin{tabular}{|c|c|c|c|c|c|c|}
\hline \multirow{2}{*}{$\begin{array}{c}\text { Order } \\
\text { Cycadales }\end{array}$} & \multicolumn{2}{|c|}{$\begin{array}{l}\text { No. of genera in Japan } \\
(\% \text { sampled })^{\mathrm{a}}\end{array}$} & \multicolumn{2}{|c|}{$\begin{array}{l}\text { No. of species in Japan } \\
(\% \text { sampled })^{\mathrm{a}}\end{array}$} & \multirow{2}{*}{$\begin{array}{r}\text { No. taxa } \\
\text { sampled } \\
1\end{array}$} & \multirow{2}{*}{$\begin{array}{c}\begin{array}{c}\text { No. } \\
\text { samples }\end{array} \\
2\end{array}$} \\
\hline & 1 & $(100)$ & 1 & $(100)$ & & \\
\hline Pinales & 6 & (83) & 22 & $(81.8)$ & 20 & 86 \\
\hline Araucariales & 2 & $(100)$ & 2 & $(100)$ & 2 & 11 \\
\hline Cupressales & 9 & $(100)$ & 14 & $(100)$ & 19 & 101 \\
\hline Pandanales & 2 & $(50)$ & 4 & $(50)$ & 3 & 6 \\
\hline Liliales $^{\mathrm{b}}$ & - & - & - & - & 4 & 11 \\
\hline Arecales & 6 & $(50)$ & 6 & (50) & 4 & 10 \\
\hline Poales & 6 & (0) & 15 & (0) & 0 & 0 \\
\hline Ranunculales & 6 & $(100)$ & 10 & (100) & 20 & 111 \\
\hline Proteales & 3 & $(66.7)$ & 7 & $(71.4)$ & 5 & 42 \\
\hline Trochodendrales & 1 & $(100)$ & 1 & $(100)$ & 1 & 10 \\
\hline Buxales & 1 & $(100)$ & 2 & $(100)$ & 3 & 4 \\
\hline Saxifragales & 9 & $(88.9)$ & 24 & $(66.7)$ & 20 & 115 \\
\hline Vitales & 4 & $(75)$ & 10 & (60) & 9 & 77 \\
\hline Austrobaileyales & 3 & $(100)$ & 4 & $(100)$ & 5 & 43 \\
\hline Fabales & 27 & $(40.7)$ & 43 & $(37.2)$ & 25 & 144 \\
\hline Rosales & 42 & $(88.1)$ & 172 & $(73.8)$ & 155 & 1014 \\
\hline Fagales & 14 & $(100)$ & 56 & (94) & 60 & 555 \\
\hline Cucurbitales & 1 & $(100)$ & 1 & $(100)$ & 1 & 6 \\
\hline Celastrales & 5 & $(100)$ & 27 & $(74.1)$ & 23 & 169 \\
\hline Oxalidales & 1 & $(100)$ & 4 & (75) & 3 & 20 \\
\hline Malpighiales & 28 & $(60.7)$ & 68 & $(60.3)$ & 43 & 215 \\
\hline Myrtales & 11 & $(63.6)$ & 16 & $(56.25)$ & 10 & 23 \\
\hline Crossosomatales & 4 & $(100)$ & 4 & (100) & 8 & 93 \\
\hline Chloranthales ${ }^{b}$ & - & - & - & - & 1 & 3 \\
\hline Sapindales & 20 & (90) & 61 & $(86.9)$ & 68 & 629 \\
\hline Malvales & 14 & $(42.9)$ & 31 & $(51.6)$ & 17 & 67 \\
\hline Brassicales & 1 & $(100)$ & 1 & $(100)$ & 1 & 2 \\
\hline
\end{tabular}




\begin{tabular}{lrcrrrr} 
Santalales & 7 & $(85.7)$ & 9 & $(77.8)$ & 7 & 37 \\
Caryophyllales & 1 & $(100)$ & 3 & $(33.3)$ & 1 & 2 \\
Cornales & 8 & $(100)$ & 28 & $(89.3)$ & 28 & 363 \\
Ericales & 31 & $(90.3)$ & 159 & $(74.2)$ & 146 & 844 \\
Icacinales & 2 & $(0)$ & 2 & $(0)$ & 0 & 0 \\
Garryales & 1 & $(100)$ & 1 & $(100)$ & 3 & 25 \\
Piperales & - & - & - & - & 2 & 8 \\
Gentianales & 25 & $(88)$ & 47 & $(74.5)$ & 45 & 161 \\
Boraginales & 3 & $(66.7)$ & 7 & $(28.6)$ & 2 & 6 \\
Solanales & 3 & $(33.3)$ & 6 & $(16.7)$ & 1 & 2 \\
Lamiales & 15 & $(80)$ & 49 & $(75.5)$ & 45 & 265 \\
Aquifoliales & 2 & $(100)$ & 24 & $(91.7)$ & 28 & 171 \\
Asterales & 5 & $(80)$ & 6 & $(66.7)$ & 7 & 21 \\
Dipsacales & 7 & $(100)$ & 51 & $(68.6)$ & 45 & 274 \\
Apiales & 11 & $(100)$ & 20 & $(85)$ & 24 & 161 \\
Magnoliales & 2 & $(50)$ & 7 & $(85.7)$ & 8 & 54 \\
Laurales & 10 & $(70)$ & 28 & $(82.1)$ & 30 & 253 \\
Alismatales & 1 & $(0)$ & 1 & $(0)$ & 0 & 0 \\
\hline Total & 361 & $(77.3)$ & 1054 & $(72.2)$ & 953 & 6216 \\
\hline
\end{tabular}

$540{ }^{a}$ The percentage of genera and species native to Japan included in the database were calculated 541 based on Satake et al. (1989).

$542{ }^{\mathrm{b}}$ denotes families that are not included in Satake et al. (1989) and, therefore, the percentage of 543 genera and species represented was not calculated. However, for these orders the number of taxa 544 and species sampled are provided. 
bioRxiv preprint doi: https://doi.org/10.1101/2021.11.11.468310; this version posted November 12,2021 . The copyright holder for this preprint (which was not certified by peer review) is the author/funder, who has granted bioRxiv a license to display the preprint in perpetuity. It is made available under aCC-BY 4.0 International license.

546

Table 3 Sampling rate for each region in Japan

547

\begin{tabular}{lrrr}
\hline Region & $\begin{array}{l}\text { No. of } \\
\text { species }\end{array}$ & \multicolumn{1}{l}{$\begin{array}{l}\text { No. of } \\
\text { species } \\
\text { sampled }\end{array}$} & $\begin{array}{l}\text { Sampling } \\
\text { rate (\%) }\end{array}$ \\
\hline Hokkaido & 217 & 193 & 88.9 \\
Honshu & 664 & 560 & 84.3 \\
Shikoku & 495 & 441 & 89.1 \\
Kyushu & 527 & 454 & 86.1 \\
Nansei Islands & 420 & 266 & 63.3 \\
Ogsawara Islands & 88 & 76 & 86.4 \\
\hline
\end{tabular}

548 


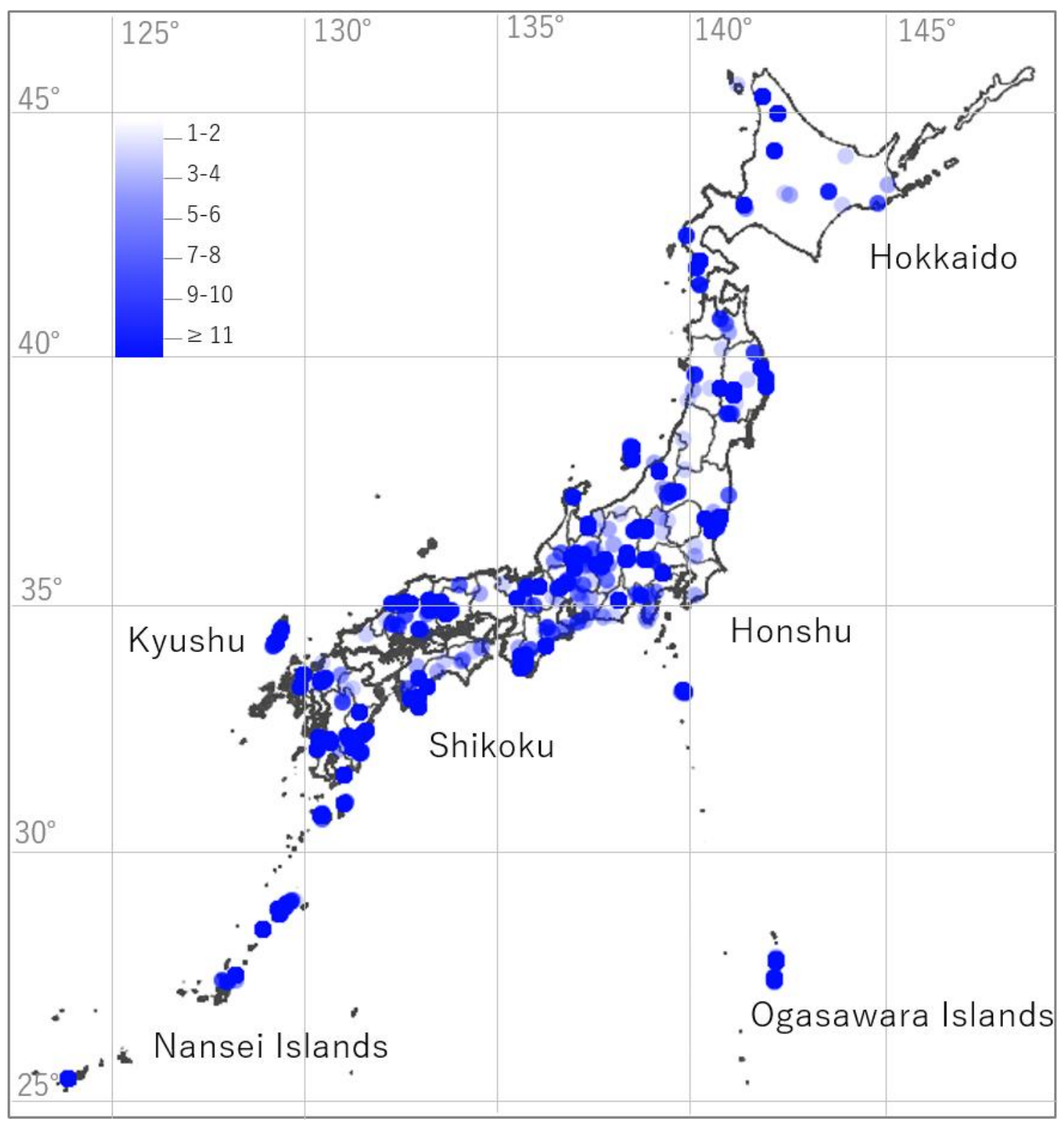

551 Figure 1 Location of all 223 sampling sites used to collect woody plants for the barcoding database. Opacity of the circles represent the number of samples per site ranging from 1 to 209 $553 \quad$ (average $=24.9$ ). 


\section{(a) Overall sequence success}

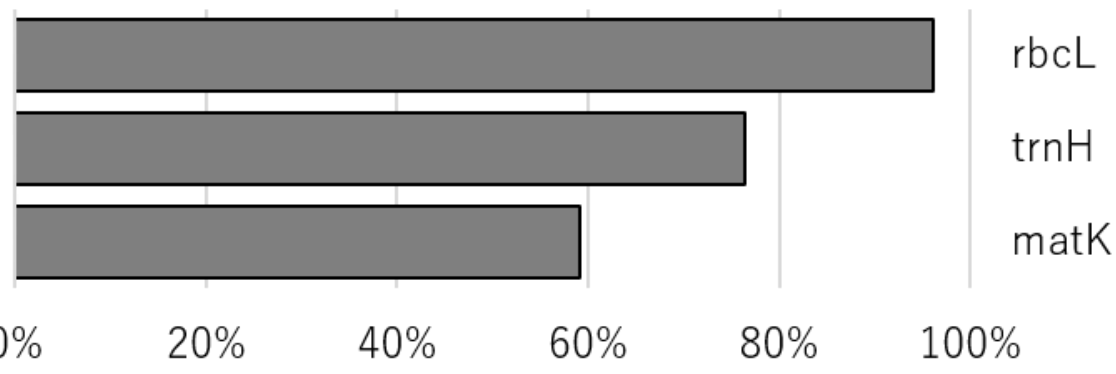

\section{(b) Overall Identification}

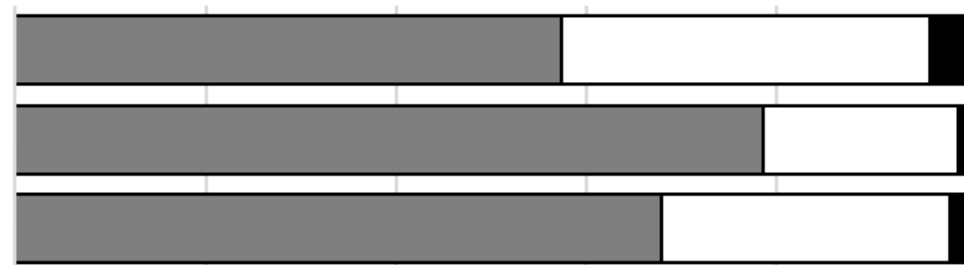

$\mathrm{rbcL}$

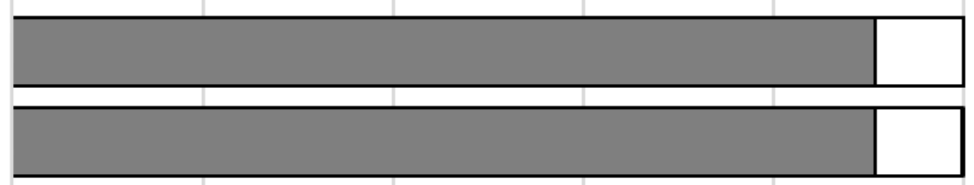

$\operatorname{trnH}$

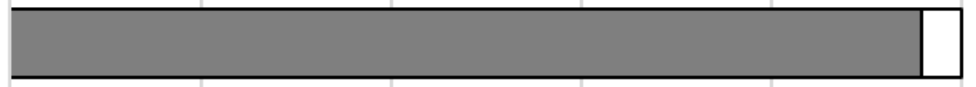

matK

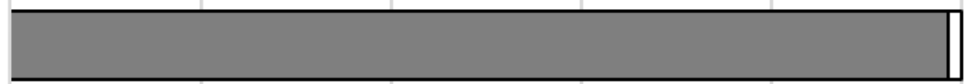

rbcL \& $\operatorname{trnH}$

$r b c L \&$ matK

$\operatorname{trnH} \&$ matK

Three region

$0 \%$

$20 \%$

$40 \%$

$60 \%$

$80 \%$

$100 \%$

\section{$\square$ Species $\square$ Genus Family}

Figure 2 The overall level of sequencing success rate for each barcode region (a) and taxonomic identification rate (at the species, genus or family level) for each individual barcode region,

558 barcode pair and all three regions (b). 


\section{(a)Sequence success (b)Species level identification}

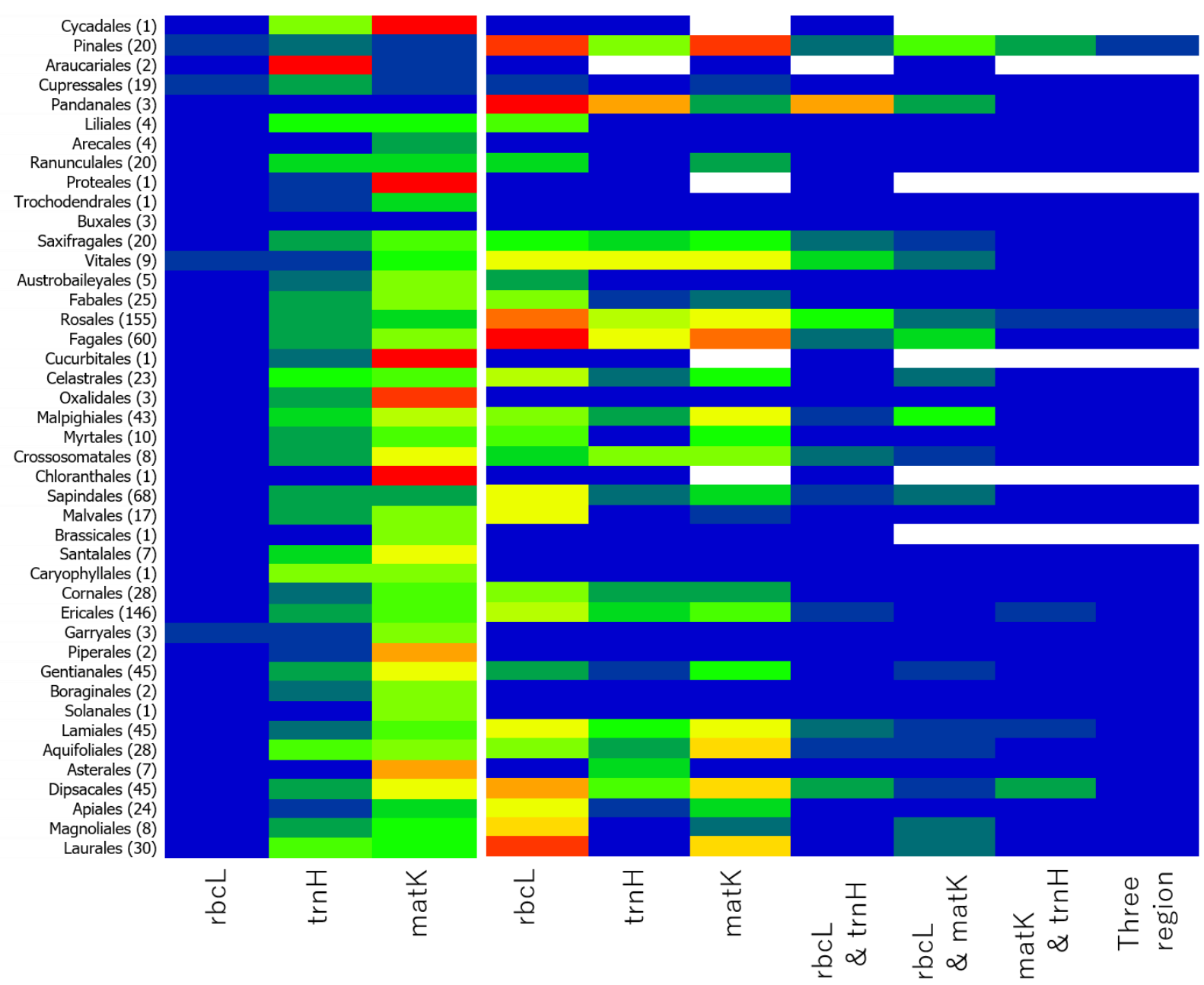

Success rate $(\%)$

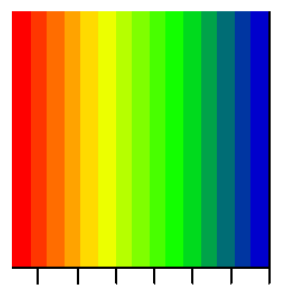

$\begin{array}{llll}40 & 60 & 80 & 100\end{array}$

Figure 3 Sequencing success rate for each barcode region and species level identification rate for each barcode region, barcode pair and all three regions for each order. Number of taxa represented by an order is shown in brackets. White blanks show no sequence region available at the order. 
565

566

567 568 $\oslash \mathrm{rbcL} \square \mathrm{trnH}-\mathrm{psbA} \square$ matK $\quad 3$ Region

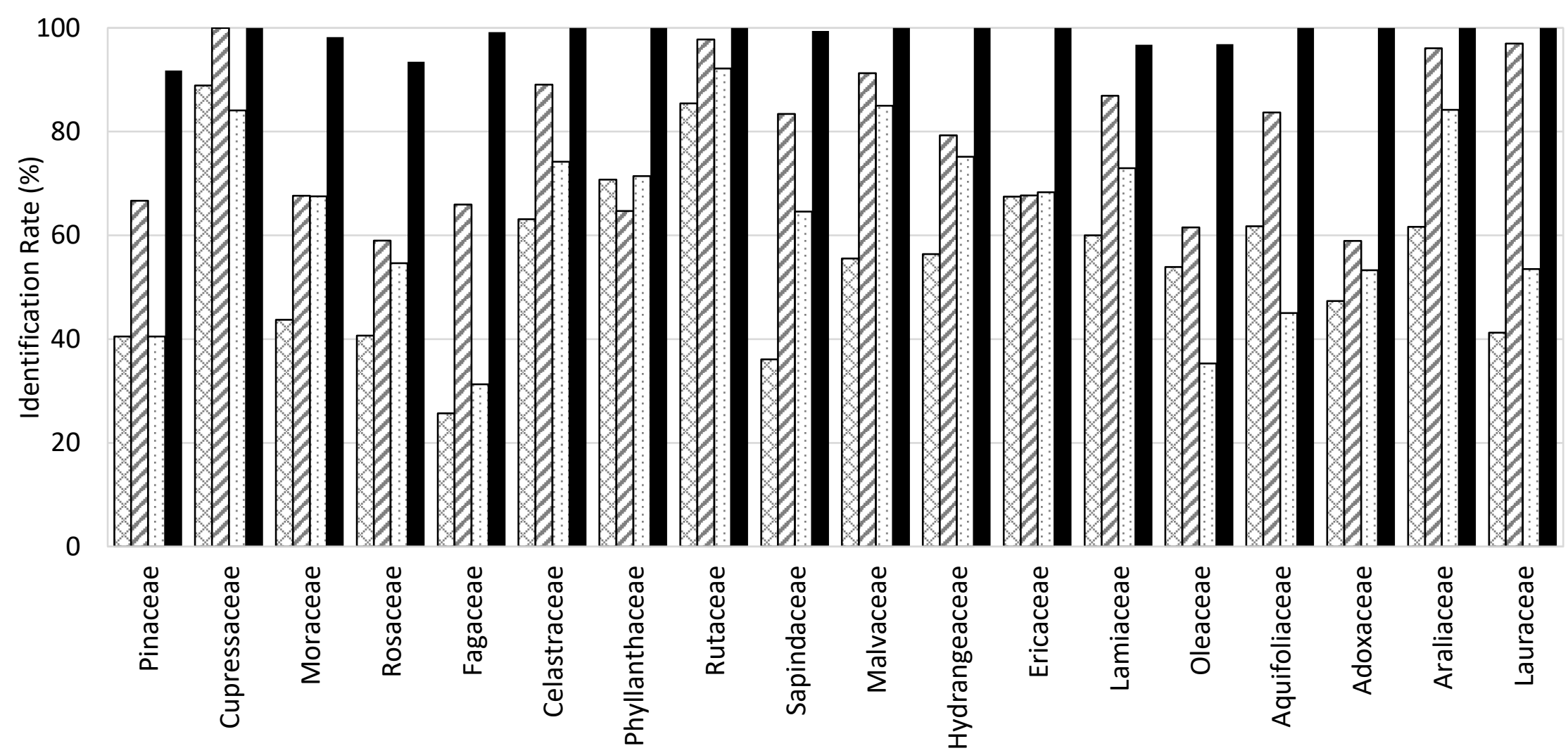

Figure 4 The species level identification rate for 18 selected plant families for which there are over 10 species in Japan and over 70\% of species were sampled and over 50\% sequence success for each three regions. 
bioRxiv preprint doi: https://doi.org/10.1101/2021.11.11.468310; this version posted November 12, 2021. The copyright holder for this preprint (which was not certified by peer review) is the author/funder, who has granted bioRxiv a license to display the preprint in perpetuity. It is made available under aCC-BY 4.0 International license.

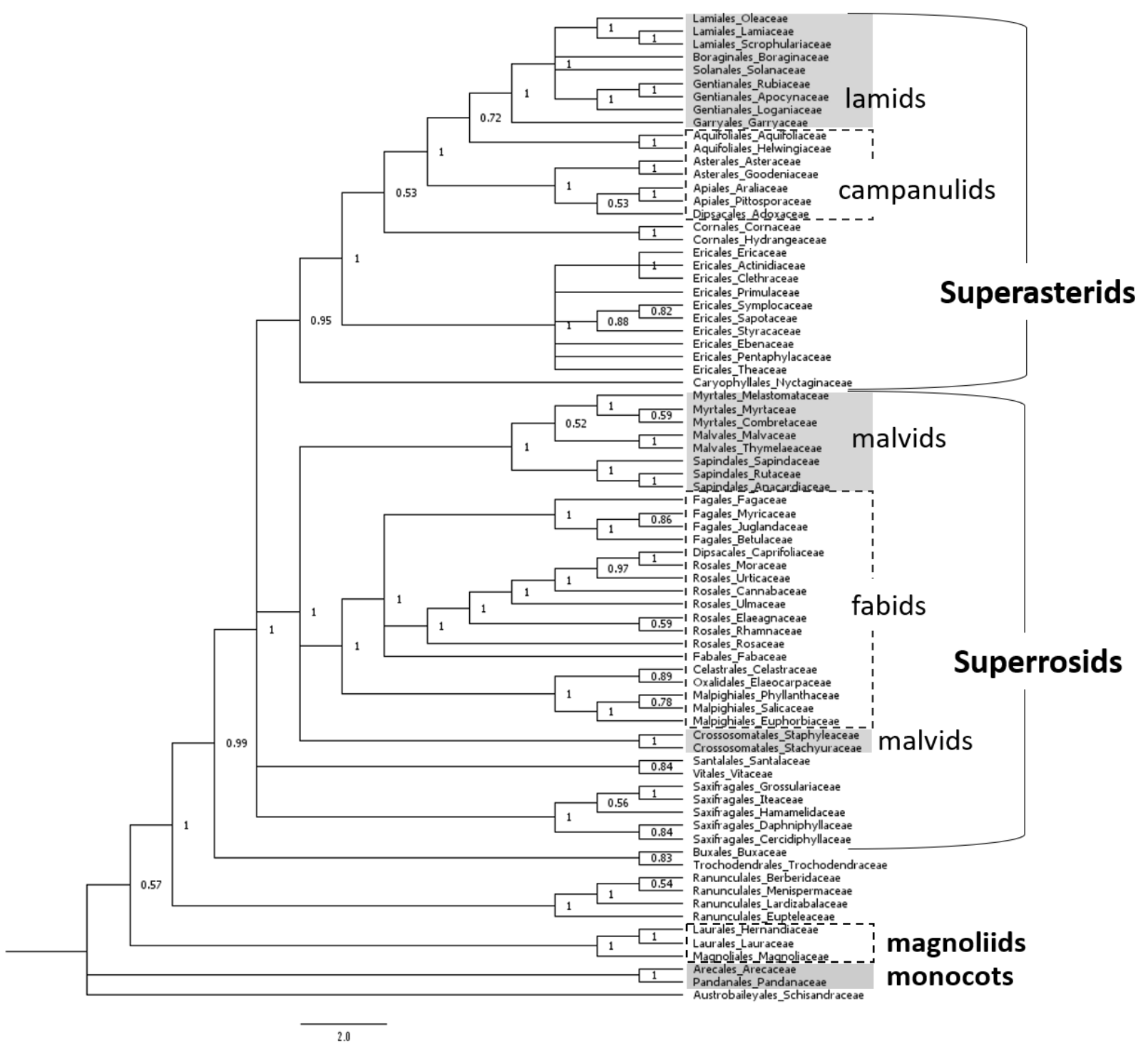

571 Figure 5 The phylogenetic tree of Japanese woody plants using all three barcode fragments (rbcL $572+$ trnH-psbA + matK).

573

574 
575 Supplementary tables

576

577 Supplementary table 1 List of samples used in this study

578 Can be downloaded from https://doi.org/10.6084/m9.figshare.16947391

579

580 Supplementary table 2 Sequencing success rates of matK using two-step PCR and order specific 581 primers

\begin{tabular}{lllcc}
\hline Order & Family & Primer name & $\begin{array}{c}\text { Sequence success rate } \\
\text { for two-step PCR (\%) }\end{array}$ & $\begin{array}{c}\text { Sequence success rate for } \\
\text { order specific primers }(\%)\end{array}$ \\
\hline Pinales & Pinaceae & CJmatK & 0.00 & 89.6 \\
Araucariales & Podocarpaceae & Thujopsis_matK & 0.00 & 93.3 \\
Cupressales & Cupressaceae & CJmatK & 0.00 & 94.9 \\
& Sciadopityaceae & CJmatK & 0.00 & 100.0 \\
& Taxaceae & CJmatK & 0.00 & 92.9 \\
Ranunculales & Berberidaceae & Anemone_matK & 44.44 & 52.6 \\
& Lardizabalaceae & Anemone_matK & 64.71 & 100.0 \\
& Menispermaceae & Anemone_matK & 69.57 & 19.0 \\
Rosales & Ranunculaceae & Anemone_matK & 53.33 & 96.6 \\
Malpighiales & Rosaceae & Sorbaria_matK & 34.33 & 93.1 \\
Sapindales & Anacardiaceae & Choerospondias_matK & 14.63 & 40.8 \\
& Meliaceae & Toddalia_matK & 42.86 & 93.0 \\
& Rutaceae & Toddalia_matK & 0.00 & 100.0 \\
Ericales & Simaroubaceae & Toddalia_matK & 17.48 & 94.8 \\
& Ericaceae & Andromeda_matK & 0.00 & 100.0 \\
\hline
\end{tabular}

Supplementary table 3 A summary of the representation of genera and species, sequence success plant family native to Japan included in the Japanese Woody Plant DNA Barcoding Database. 